\title{
Bilateral Lipoma Arborescens - A Proliferative Case Showing Disease Progression in an Adolescent Male
}

\author{
Garin Gil Hecht ${ }^{1}$, Justin Neal Hopkins ${ }^{1}$, Zachary C Lum ${ }^{1 *}$, Saba Fatima Ali ${ }^{2}$ and Cassandra Alda Lee ${ }^{1}$ \\ ${ }^{1}$ Department of Orthopaedic Surgery, University of California Davis, USA \\ ${ }^{2}$ Department of Pathology and Laboratory Medicine, University of California Davis, USA
}

Submission: April 17, 2018; Published: April 25, 2018

*Corresponding author: Zachary C Lum, Department of Orthopaedic Surgery, University of California Davis, 4860 Y Street, Suite 3800, Sacramento, CA 95817, USA, Tel: (916) 734 2807; Email: zacharylum@gmail.com

\section{Abstract}

We describe a case of extensive symptomatic bilateral lipoma arborescens of the knee in a 19-year-old man who suffered from recurrent knee effusions for many years. This patient had MRI evidence of progression of disease prior to arthroscopic intervention. He was treated with bilateral complete arthroscopic synovectomies, demonstrating no evidence of cartilage wear.

Conclusion: Lipoma arborescens is a progressive disease. Timely diagnosis and treatment may prevent disease evolution and sequela.

Keywords: Bilateral lipoma arborescens; Arthroscopic complete synovectomy; MRI

\section{Introduction}

Lipoma arborescens is a rare cause of knee joint pain and effusion. It is characterized by a frond-like, hypertrophic synovium that may cause symptomatic effusions [1,2]. The term originates from "arbor," meaning "tree", which describes the gross appearance of the mass. Lipoma arborescens typically occurs unilaterally in the knee, although cases of bilaterality, extraarticular disease, and locations distant to the knee joint have been described $[1,3,4]$. Hoffa attributed the term "lipoma arborescens" to Johannes Muller in 1904, referring to adipose disturbances in the knee joint [5]. In 1953, Arzimanoglu presented a case of a 19-year-old girl with bilateral symptoms, diagnosed by open excisional debridement [6].

Today, it is commonly diagnosed through MRI as nodules with a frondose morphology and hyperintense signal on T1 and T2 sequences. It is confirmed by histologic analysis as fat cells beneath the synovial tissue with small amounts of lymphocytes and plasma cells surrounding capillaries [1]. Little is known about the etiology and progression of lipoma arborescens. While MRI enables both non-invasive diagnosis in symptomatic patients and incidental discovery of lipoma arborescens in asymptomatic patients, there is no study to date documenting progression of disease to prolific pan-compartmental involvement.

\section{Presentation of the Case}

The patient was a 19-year-old male referred to our clinic following six years of recurrent knee effusions and two recent episodes of left patella dislocation events. He had congenital transposition of the great arteries, requiring an arterial switch procedure in infancy and a subsequent aortic valve replacement at age 9, resulting in long-term use of warfarin for anticoagulation. Pediatric orthopaedic and rheumatology specialists had attributed his effusions to be due to hypertrophic synovium from chronic hemarthroses when they began occurring in his early teen years. An MRI of his left knee at age 13 showed arboreal hypertrophy of the infrapatellar fat pad, though at the time this was not diagnosed as lipoma arborescens (Figure 1)

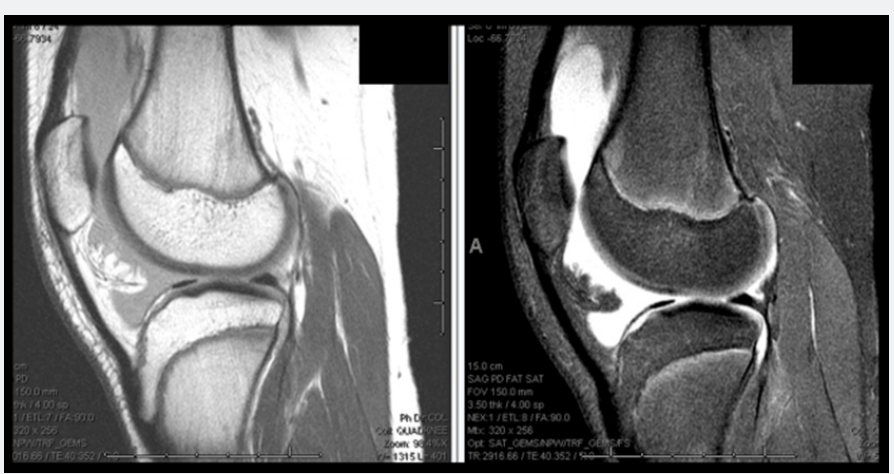

Figure 1: MRI at age 13 showing sagittal T1 and T2 images with evidence of arboreal proliferation of the infrapatellar fat pad. 


\section{Juniper Online Journal of Orthoplastic \& Microsurgical Reconstruction}

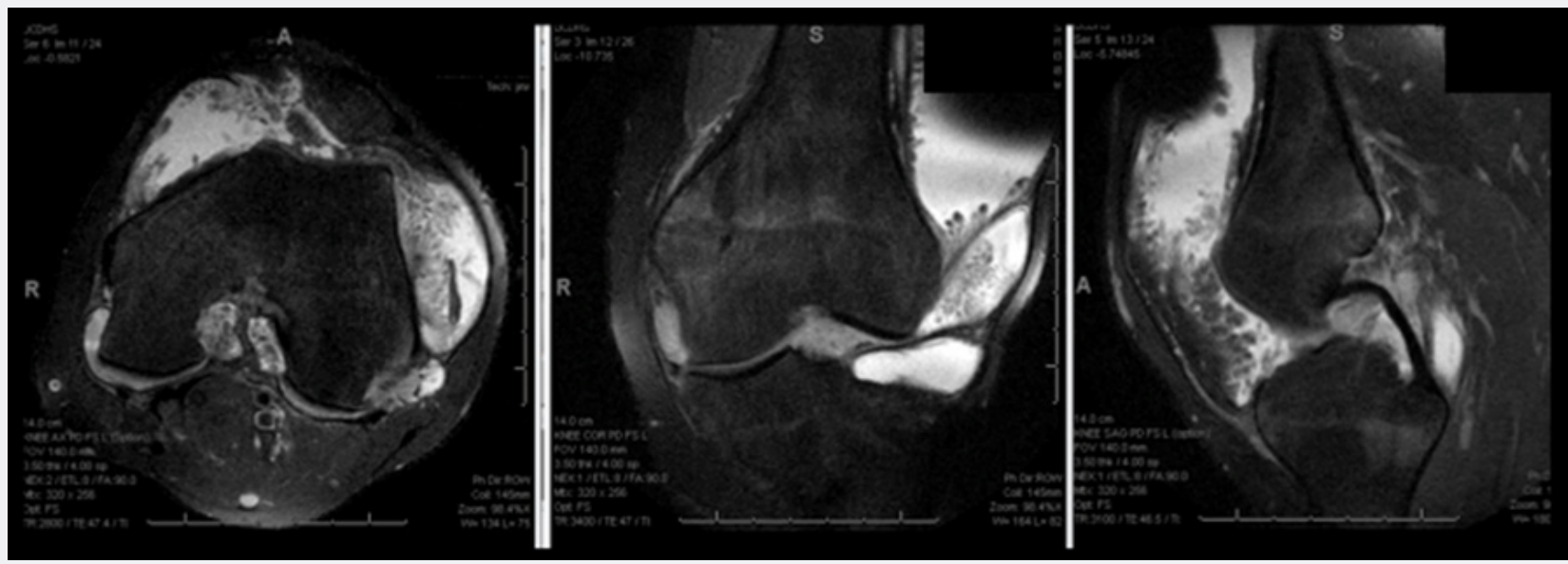

Figure 2: Axial, Coronal, and Sagittal T2 MRI cuts showing expansive geographic involvement of the patient's left knee at age 19.

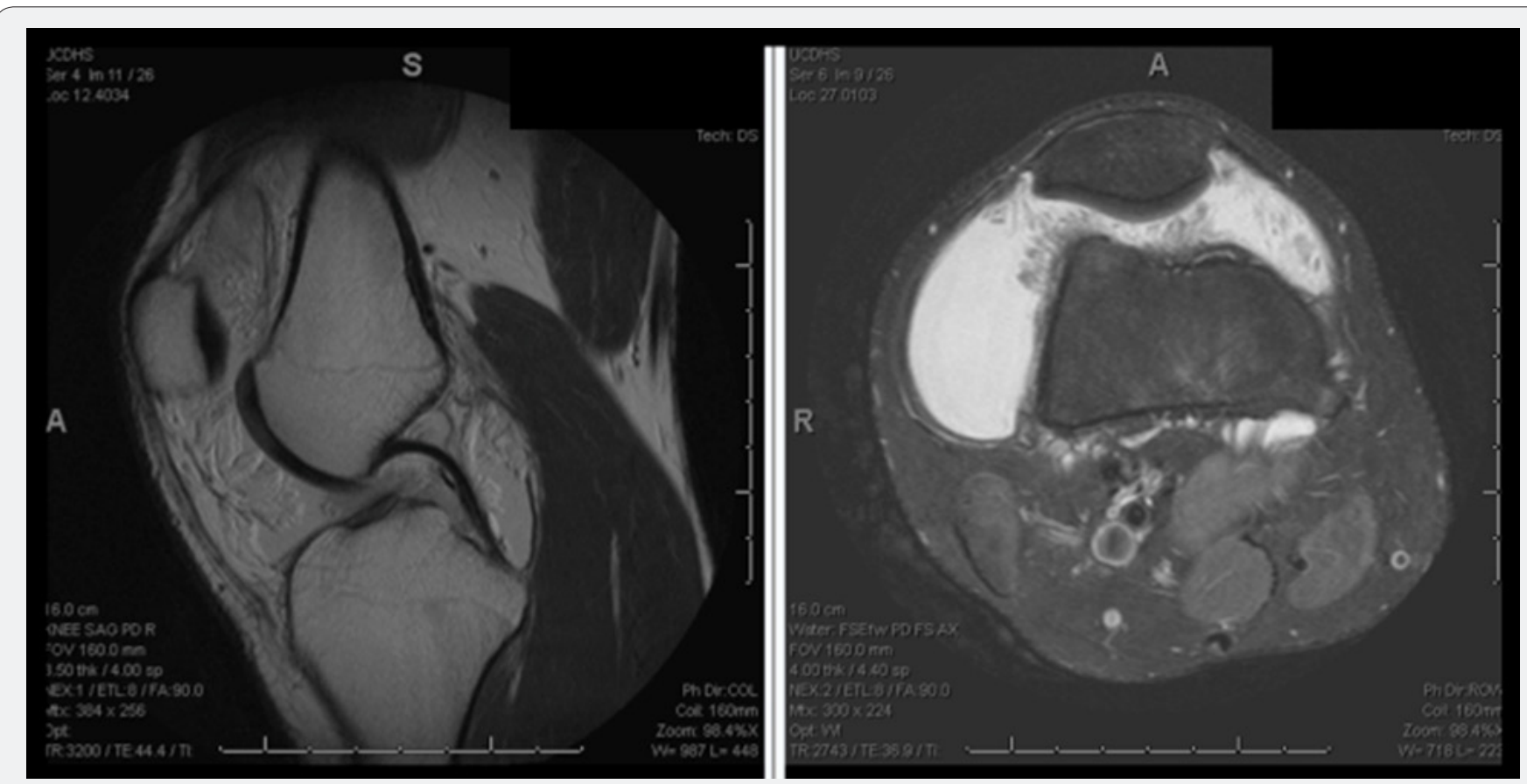

Figure 3: Sagittal T1 and Axial PD MRI images showing involvement of the patient's right knee after presentation.

In addition to cartilaginous injury to the medial facet of the patella from his dislocations, the new MRI of his left knee revealed diffuse fatty hypertrophy of his synovium, with villous and arboreal architecture throughout the knee joint (Figure 2). An MRI was ordered for his contralateral knee given its non-painful large effusion showing similar findings of the synovium (Figure 3). Due to the severity of his recurrent effusions and difficulty performing his job duties in the automotive industry, the patient elected to have bilateral diagnostic arthroscopies with synovial biopsies and complete arthroscopic synovectomies.

\section{Procedure}

The patient was admitted to the hospital for bridging therapy of his anticoagulation. On hospital day \#3, he underwent sequential bilateral knee arthroscopy, beginning with the left knee, which is described in detail. Once anesthetized, a physical exam revealed stable ligamentous testing and a grade $3+$ effusion. Under tourniquet use, the knee joint was entered through an anterolateral portal and approximately $150 \mathrm{cc}$ straw-colored synovial fluids were immediately evacuated. Our diagnostic arthroscopy ensued, showing a medial patellar facet 
injury with a corresponding loose body in the lateral gutter and, most impressively, innumerous fatty-appearing villous tumors projecting from the synovium throughout each compartment of the joint (Figures $4 \mathrm{a} \& 4 \mathrm{~b}$ ). The cruciate ligaments were normal appearing, but both menisci were encased in fatty tumors growing from the capsule into the joint, with the medial meniscus additionally being subluxated off of the tibial plateau surface. There was no evidence of cartilage wear on the tibiofemoral articular surfaces.

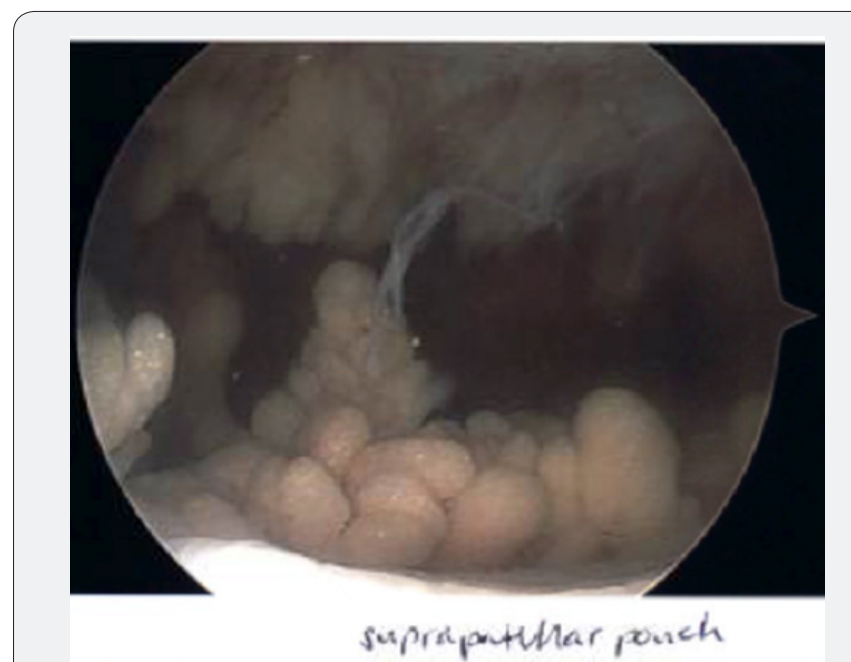

Figure 4a: Arthroscopic image of suprapatellar pouch, showing diffuse frond-like fatty projections of synovium.

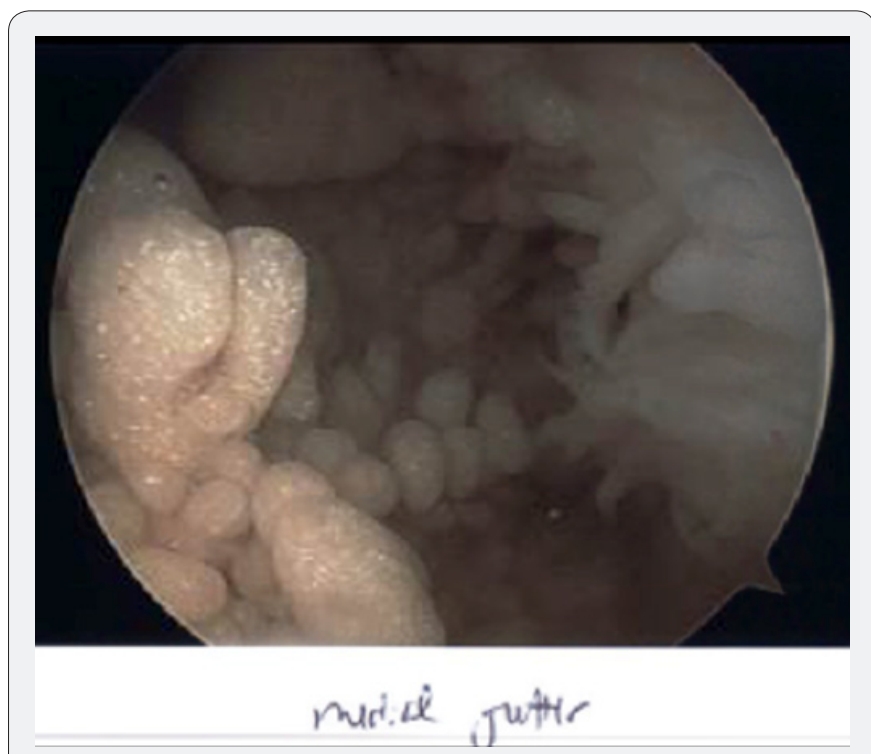

Figure 4b: Arthroscopic image of the medial gutter, noting the extensile burden of disease.

Multiple biopsies were taken from the synovial projections and the capsule itself. Complete arthroscopic synovectomy and debridement was then performed, which included using an accessory posteromedial portal for instrumentation to the posterior compartment of the knee joint (Figure 5). His postoperative recovery in the hospital was uneventful, and his Coumadin therapy was resumed. At his 3-week post-operative visit, the patient had some persistent pain and ongoing effusion, attributed to surgical hematoma. This effusion resolved slowly; unfortunately, he did suffer some recurrence of effusions. Surgical pathology from each knee showed proliferative synovia with primarily villous architecture of adipose tissue without atypia (Figure 6). A focal lymphoid reaction was present, and no pigmentation consistent with pigmented villonodular synovitis (PVNS) was found (Figures 7 \& 8).

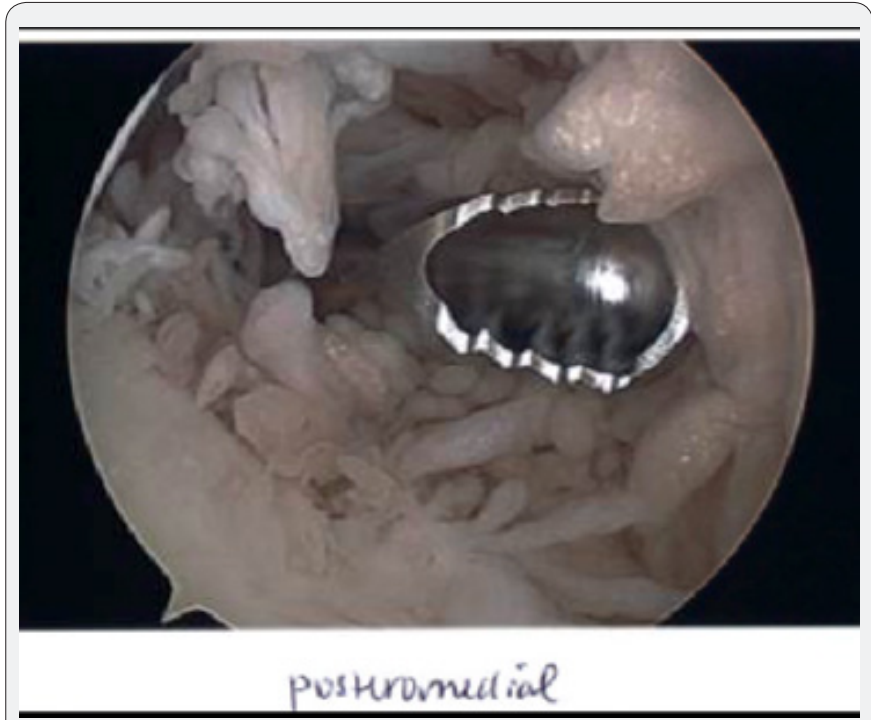

Figure 5: Arthroscopic image of the posterior compartment of the knee including an arthroscopic shaver introduced through a posteromedial portal.

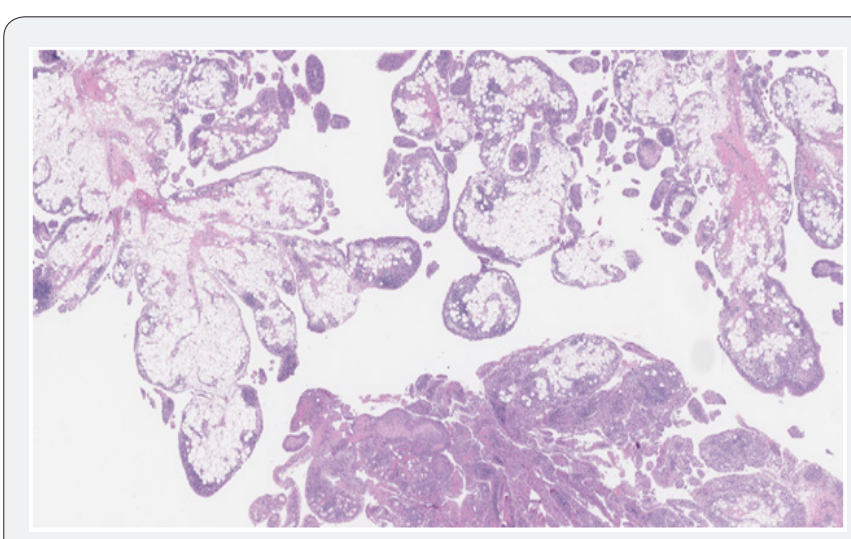

Figure 6: Low power view of the synovial membrane that demonstrates a villous-like proliferation of the synovium with papillary projections expanded predominantly by mature adipocytes and focal areas of stromal fibrosis, vascular congestion, and a dense chronic inflammatory infiltrate (hematoxylin-eosin, 1x). 


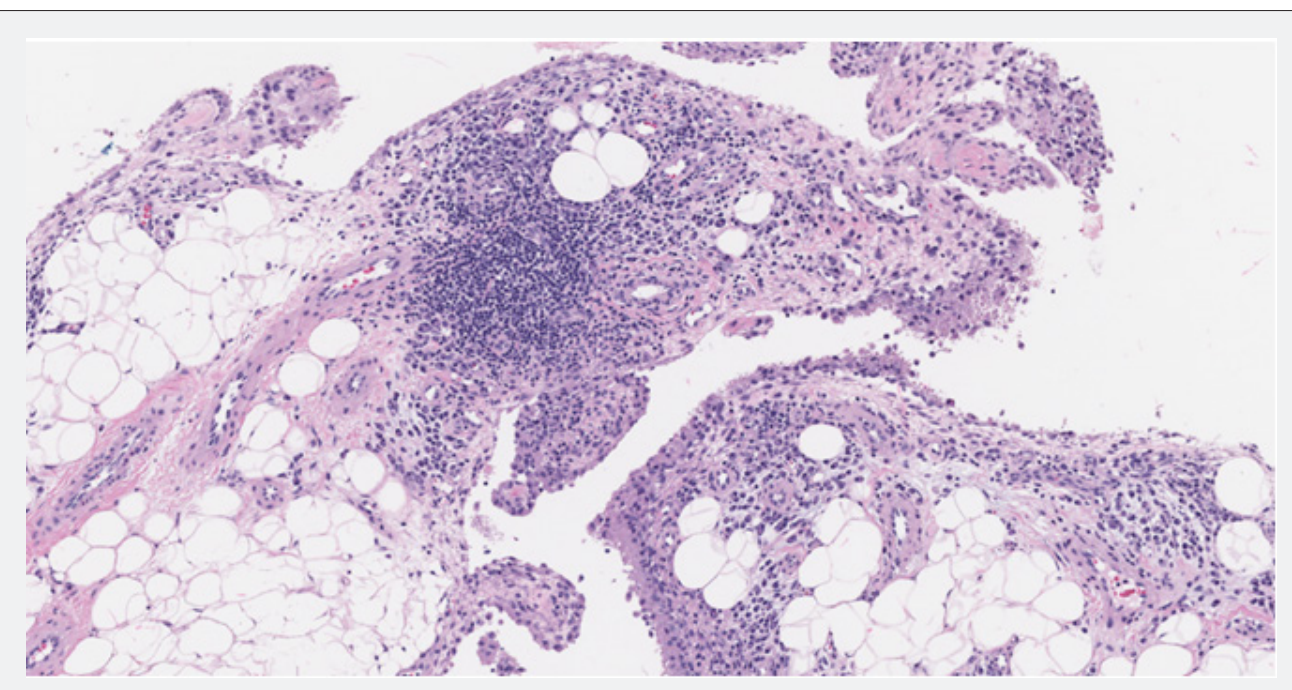

Figure 7: Medium power view showing a chronic inflammatory infiltrate characterized by diffusely scattered plasma cells and lymphocytes with focal lymphocytic aggregates (hematoxylin-eosin, 11x).

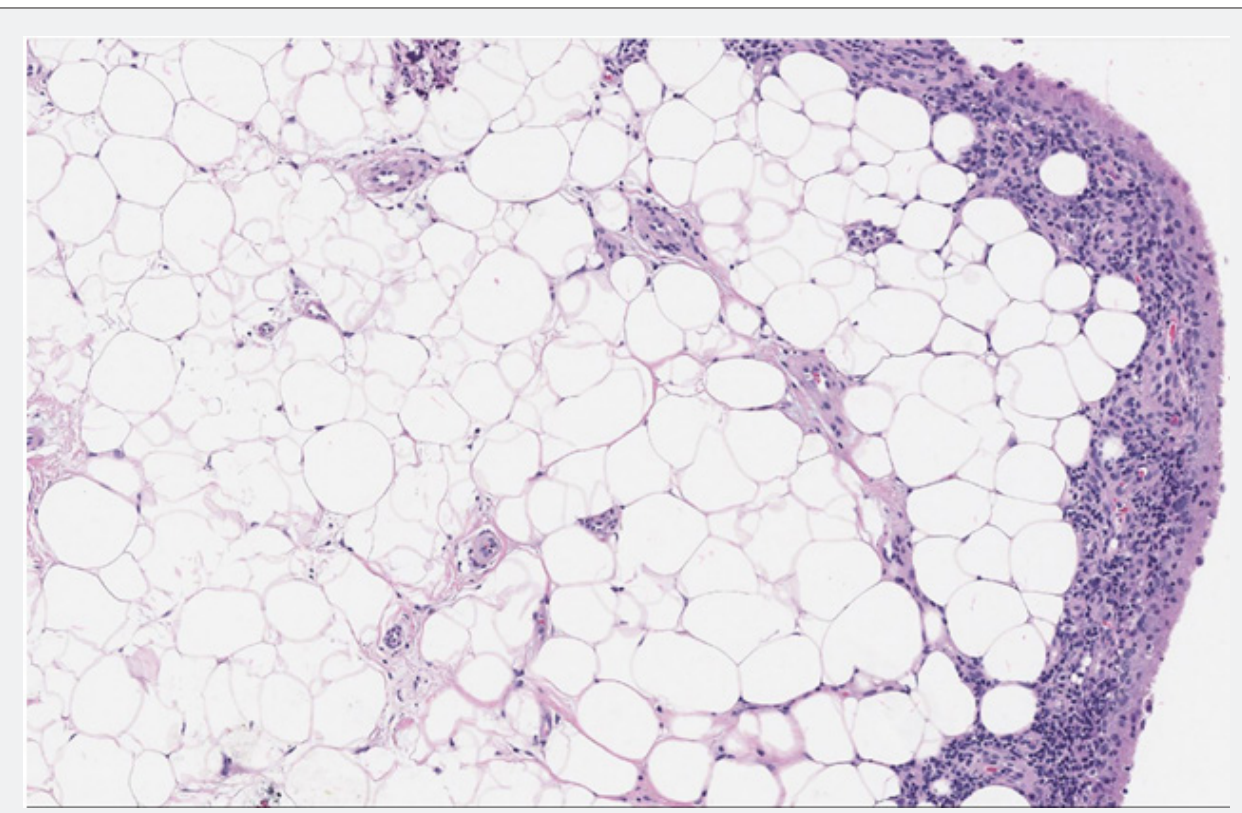

Figure 8: High Power view of subsynovial benign, mature adipocytes without atypia and hyperplastic synovial lining (hematoxylin-eosin, 20x).

\section{Discussion}

To our knowledge, this is the first case of lipoma arborescens with sequential MRIs demonstrating unequivocal proliferative progression of pathology prior to surgical intervention. Differentiating lipoma arborescens from chronic synovitis and PVNS is important, as a radical synovectomy may be necessary to treat the latter while arthroscopic management of the former has been shown to limit recurrence $[1,8]$. While pan-compartmental involvement did occur in our case, there was no extra-articular propagation, which can occur with widespread PVNS. Sequelae of symptomatic lipoma arborescens are not known. A recent report suggests that osteoarthritis may result from delays in the definitive treatment of this pathology [4]. While our patient did show progression of his benign neoplasia over a six-year period marked by recurrent effusions, MRI and arthroscopic evaluation showed no evidence of cartilage wear at the time of surgery, even with the subluxated medial meniscus.

Our report provides no evidence regarding the etiology of lipoma arborescens. Some hypotheses suggest osteoarthritis or inflammatory arthritis as a cause of lipoma arborescens, while others have investigated the role of steroid injections and diabetes $[3,8]$. While patella dislocations were found in $6 \%$ of patients with lipoma arborescens [2], our patient had only left sided dislocation events with a bilateral disease process. Furthermore, disease burden may be limited to a specific compartment in the knee, pancompartmental, or even polyarticular, which highlights 
the marked variability of this poorly understood disease [9]. The diagnosis of lipoma arborescens relies on clinical, MRI, and histopathologic studies. Although the etiology and consequences of this disease are still not well known, there appears to be a wide spectrum with different subsets. Ultimately, adequately diagnosing and treating these patients may prevent progression of the disease.

\section{References}

1. Sailhan F, Hautefort P, Coulomb A, Mary P, Damsin JP (2011) Bilateral lipoma arborescens of the knee: a case report. J Bone Joint Surg Am 93(2): 195-198.

2. Vilanova JC, Barceló J, Villalón M, Aldomà J, Delgado E, et al. (2003) MR imaging of lipoma arborescens and the associated lesions. Skeletal Radiol 32(9): 504-509.

3. Howe BM, Wenger DE (2013) Lipoma arborescens: comparison of typical and atypical disease presentations. Clin Radiol 68(12): 12201226.

This work is licensed under Creative Commons Attribution 4.0 License DOI: 10.19080/JOJOOS.2018.01.555568
4. Natera L, Gelber PE, Erquicia JI, Monllau JC (2015) Primary lipoma arborescens of the knee may involve the development of early osteoarthritis if prompt synovectomy is not performed. J Orthop Traumatol 16(1):47-53

5. Hoffa AA (1904) The influence of the adipose tissue with regard to the pathology of the knee joint. JAMA 43: 795-796.

6. Arzimanoglu A (1957) Bilateral arborescent lipoma of the knee. J Bone Joint Surg Am 39A(4): 976-979.

7. Kamran F, Kavin K, Vijay S, Shivanand G (2015) Bilateral lipoma arborescens with osteoarthritis knee: Case report and literature review. J Clin Orthop Trauma 6(2): 131-136.

8. Miladore N, Childs MA, Sabesan VJ (2015) Synovial lipomatosis: A rare cause of knee pain in an adolescent female. World J Orthop 6(3): 369373.

9. Yan CH, Wong JWK, Yip DKH (2008) Bilateral knee lipoma arborescens: a case report. J Orthop Surg (Hong Kong) 16(1): 107-110.

\section{Your next submission with Juniper Publishers} will reach you the below assets

- Quality Editorial service

- Swift Peer Review

- Reprints availability

- E-prints Service

- Manuscript Podcast for convenient understanding

- Global attainment for your research

- Manuscript accessibility in different formats ( Pdf, E-pub, Full Text, Audio)

- Unceasing customer service

Track the below URL for one-step submission https://juniperpublishers.com/online-submission.php 